\title{
Study on Debord's Thoughts of Cultural Revolution in the Perspective of Spectacle
}

\author{
Xiaoqin Yan \\ College of Literature and Journalism \\ Sichuan University \\ Chengdu, China
}

\begin{abstract}
Based on the context of consumer culture in the second half of the 20th century, Guy Debord puts forward the concept of "spectacle" to criticize the capitalism making use of the mists of spectacle created by the mass media, which causes people to lose their sense of reality, and deepens the degree of alienation. In order to reawaken people's experience of real life, the important task of the cultural revolution was put forward, and it was finally implemented in levels of both "everyday life" and "art", and revolutionary tactics such as "dérive" and "detournement" were adopted to try to break the habitual thinking and action so as to acquire the true situation. Cultural and political revolutionary imagination has effectively being promoted in the wakefulness.
\end{abstract}

Keywords-Guy Debord; cultural revolution; everyday life; art

\section{INTRODUCTION}

Guy-Ernest Debord (1931-1994) was a famous French thinker, radical filmmaker, one of the leaders of the Parisbased artistic and political avant-garde group known as the Situationist International, and also an important pioneer of the post-Marxism. Spectacle, as an important key word was a center in his theoretical contemplation and artistic practice. His most well-known masterpiece The Society of the Spectacle (a total of 9 chapters, 221 sections, about 60,000 words, similar to a collection of mottoes written in a pithy style) is known as "contemporary Capital" revealing the evolutionary logic of "commodity fetishism" to "spectacle fetishism" in the context of consumer culture, and a new manifestation of "alienation", which has important historical and practical significance. However, most of Debord's current researches have positioned him as a pure theorist or poetic artist, not paying enough attention to his radical ideas of cultural revolutionary. This article intends to discuss his ideas about culture revolution and to restore a revealer of the visual disciplined society in both theory and practice levels.

\section{THE SOCIETY OF THE SPECTACLE: THE REASON FOR THE CULTURAL REVOLUTION}

Undoubtedly, cultural turn has been an important and also an inevitable event in western theoretical discourse since the 20th century. As we know, some internal research methods such as Russian formalism, new criticism, and structuralism had flourished for a long time. However, in the face of a new era of turbulence and radical change, this practice of exiling history, politics, and culture out of the text is inevitably replaced by new theoretical discourse because of its strong closure. Hence culture researches become an important way and strategy for intellectuals to intervene in reality and politics. The common topic they are concerned about is how to criticize capitalism from a cultural perspective and carry on new revolution in the context of capitalism, so does Guy Debord. In order to understand deeply about his ideas of cultural revolutionary and fairly evaluate its effect, we first need to comprehend his views about "spectacle", which is a widely used concept in Debord's books. However, he refused to define it precisely and clearly, and then gave it a critical connotation through the seemingly fragmented but focused discussion. Firstly, from an etymological point of view, "spectacle" first appeared in the literature of Hebrew Bible, which was used to describe the beauty of the holy city of Jerusalem, including Solomon temples, castles, and palaces. It means that the earliest meaning of spectacle has a visual aesthetic significance. Secondly, from the perspective of the Chinese translation, there are two most popular translations at present, one is "Qi Guan" and the other is "Jing Guan". Both of them have the visual meaning in the etymological sense, but scholars generally agree that the latter is more consistent with Debord's original meaning. Because no matter how it is explained, the translation of "Qi Guan" highlights that the object to be watched has the intention of attracting the eyeball, but the translation of "Jing Guan" appears to be more neutral and objective, with no strong emotion, and it can present a unique phenomenon in a specific era context. Actually, in Debord's view, spectacle has become a universal phenomenon. In other word, the dominant nature of contemporary society is mainly manifested as a demonstrated picture. Through the analysis and discussion about Debord's concept of spectacle from the etymological and translation perspective, it can be concluded that this concept is not only related to vision, but it is ubiquitous, which is closely related to each other, and even present a causal relationship. In connection with the context of consumer culture in which Debord was living, it is not difficult to understand why he used "spectacle" to summarize the forms of expression of the new period of capitalist development. 
After World War II, although people were still immersed in the pessimistic disappointment, the economy developed rapidly, which has led to revolutionary changes in the social structure and economic form? What so called "consumer society" has emerged instead of the commodity society resulting in a comprehensive reform of social life style, and a complete change of people's experience and imagination about culture and society? This is highlighted by the rapid development of the communications industry, which is dominated by mass media such as television, film and publishing. They are different from the oral or printed media transmission methods of the past. The advantages of visualized images have once again become a means available to capitalism. American famous sociologist Daniel Bell once pointed out: "Today, the dominant outlook is visual. Sound and sight, and particularly the latter, organize the aesthetics and command the audience. It could almost not be otherwise in a mass society." (Bell, 1976:154) Capitalism is making full use of this development and changes to create overwhelming advertisements to stimulate popular desires for consumption. This means that the capitalist mode of production will transit from "existence to possession" to "occupation to manifestation". With the pervasive of visual culture, Debord made a clear statement in the society of the Spectacle, "The entire life of societies in which modern conditions of production reign announces itself as an immense accumulation of spectacles. Everything that was directly lived has moved away into a presentation." (Debord, 1970:2) This can be said to be a direct rewrite of one sentence of Marx's Capital, "The social wealth that occupies a dominant position in the capitalist mode of production manifests itself as a huge accumulation of goods." (Marx, 1953:1) This means that the traditional capitalist production has developed into a new stage. Material production and commodity circulation no longer become dominant, but the visual image or image produced by the modern media have dominated everything. Marx's "commodity fetishism" hence gave place to Debord's "spectacle fetishism".

Then, what features of the spectacle can be combined with capitalism? Debord believes that the visual experience created by the mass media has been elevated to the position previously enjoyed by tactile sense. It is the easiest way to deceive, and it is also the most effortless way to adapt in the universal abstraction of today's society, allowing people to gain a seemingly true survival experience in the visual. "The commodity is this factually real illusion, and the spectacle is its general manifestation." (Debord, 1970:24) Therefore, unlike commodities, the biggest feature of spectacle is that it is illusory and deceptive. "Within a worldly really on its head, the true is a moment of the false." (Debord, 1970:4) "Seeing is not necessarily true" has become an accurate annotation of the characteristic of spectacle. Later Belden Fields and Steven Best expressed the similar meaning in the interpretation of the "spectacle". They think that the spectacle refers to "a small number of people performing, some kind of performance that most people watch silently". (Gorman, 1990:767) The so-called minority and majority here actually referred to the capitalists and the mortal beings manipulated by the capitalists. Since it is performance, it means that there is a huge gap between realities. A false world is separated. The logic of the capitalist domination has changed accordingly. It uses a depoliticized illusion to dress itself up as supreme good, and never directly interferes with the life of the people. It just continuously creates people's desires and needs. "Spectacle" leads people to constantly chase the so-called fashion and gradually lose their true needs. "Without doubt our epoch...prefers the image to the thing, the copy to the original, the representation to the reality, appearance to being..." (Debord, 1970:1) The fact that Debord quoted Feuerbach in the introductory chapter actually indicates that the current society is only a modern version of religious dictatorship. He further pointed out that spectacle is not merely the aggregation of a false image, but the social relations of people. It is the social relations mediated by the image, and it has become universal cognition. As he said: "Spectacle cannot be understood as the abuse of a world of vision, as the product of the techniques of mass dissemination of images...It is a vision of the world which has become objectified." (Debord, 1970:2) This is also a further development of the ideas of Marx, Lukács and others, except that the "things" here are replaced by images. Capitalists adopt such a non-violent implicit control method to easily accomplish the enslavement of people's thoughts, so that people are willing to bow their heads. It is a hidden ideology. The advanced techniques of capitalism's ruling apparently deepened what Marx called "alienation". People are manipulated by spectacles, living in false consciousness, away from reality, and have already penetrated into people's everyday lives, making the rule of capitalism more consolidating and non-destructive.

\section{EVERYDAY LIFE AND ART: THE CARRIER OF THE Cultural ReVOLUTION}

Debord profoundly analyzed the new characteristics of capitalist development and revealed a new form of capitalist rule. At the same time, he also realized that the criticism of theory is limited and people must put it in action. Otherwise, "spectacle" can only be used as an empty concept to become another spectacle. Therefore, he actively pursued the revolutionary path with the attitude of a revolutionary, hoping to reawaken people's realistic feeling and get rid of the slavery of the unreal spectacle society. Debord clearly realized that the communist revolution did not happen and today's revolution can no longer resort to traditional political struggle and resistance. It can only resort to a cultural approach and open up a new revolutionary dimension. Debord wrote a Report on the Construction of Situationist Tendency's Conditions and Action on the eve of the establishment of SI in May 1957. He declared: "First, we believe the world must be changed. We desire the most liberating possible changes of the society and life in which we find ourselves confined. We know that such a change is possible by means of pertinent actions. (Debord,2010:29) In this report, Deborde briefly discusses the issues of culture and ideology in modern capitalist society and puts forward urgent practical tasks. "We must everywhere present a revolutionary alternative to the ruling culture; coordinate all the researches that are currently taking place but which lack a comprehensive perspective; and incite, through critiques and propaganda, the most advanced artists intellectuals of all 
countries to contact us in view of a collective action." (Debord, 2010:50) He emphasized the necessity and possibility of the Cultural Revolution, and tried to form an international alliance and become an overwhelming force. Thus, Situationist International came into being. Its establishment not only has deep roots in literature or avantgarde art, such as Dada, surrealism, but also incorporates other avant-garde theories at that time, including the International of Experimental Artist, Letterist Movement and Letterist International, Bauhaus Impression Movement International, etc. The members are architects, artists, writers, theorists and so on. In Debord's Theses on the Cultural Revolution, He believes that "An international association of situationists can be seen as a union of workers in an advanced sector of culture, or more precisely as a union of all those who claim the right to a task now impeded by social conditions; hence as an attempt at an organization of professional revolutionaries of culture." (Debord, 2010:91) The reason for their coexistence is that people still live in the corruption system of the old cultural superstructure. This is a culture that is alienated and materialized. It will certainly destroy people's rebellious awareness and creativity and make people become numbness and obedience, in later Marcuse's words it is "one-dimensional man". Therefore, they attempted to rebel against and transform the alienation of reality with various off-site artistic expressions, and actively constructed specific living situations to obtain more perfect and realistic living conditions. So, what is "situationist construction"? In the first issue of SI magazine, a clear definition was made: "The moment of life that is specifically constructed by the collective organization of a unified environment and event game." We can regard it as a breaking point between life and art. In it, both art and life undergo a decisive change at the same time, and this breaking point is the moment to reawaken the sense of reality. Therefore, it can be said that from the very beginning of the establishment of Situationist International, it was in an avantgarde attitude to attempt to rebel against the alienation caused by the preexisting capitalist order through a cultural revolution. Debord, by holding high the banner of both poetry and politics, has made a breakthrough in the theory and practice of art and everyday life. It combines the two seemingly separate and contradictory aspects into contextual construction to achieve the sense of real existence.

First, as a visual artist, Debord was deeply influenced by the early avant-garde culture, especially his favorite surrealist poet, Lautréamont, and rebuilt his subversive and rebellious spirits, coupled with the infiltration of other avantgarde groups. Debord has always used the art revolution experiment as a weapon of the cultural and social revolution and is committed to seeking new creative expressions of art and politics. This was clearly reflected in his film practice creation, because the visual art of the film has always been regarded as an important form of spectacle presentation. It uses various techniques to present people with continuous images, coherent plots and complete narrative. But when you watch several of the films he created, you may come to this question, is this film? He tore off the images from the screen, breaking the coexistence of video and film, as well as the normal and even beautiful imagination of people about the screen and plot, etc., and completed their own situation construction in people's anger and shouting. It should be said that through the film art, he completed the separation effect that Brecht tried to complete with an epic drama, reconstructing the real situation of the subject. Like other avant-garde artists, Debord also plays the role of prophet, which Bourdieu derives from Weber's religious sociology, with an "anti-artist" attitude to resist the old culture and the false feelings brought about by the spectacle resorting to the subject.

Of course, Debord is not only actively practicing its own revolutionary ideas in the field of art, everyday life is also another important battle field he is concerned about. Everyday life is an important dimension closely related to the individual, but it has long been subjected to a state of aphasia due to the masking of traditional metaphysical discourse. Since the 20th century, with the expansion of capitalism on a global scale and the development of human rationality, the "critics of everyday life" has gradually entered the critical field of view, and has urgently incorporated it into the current cultural and political system of irrational rebellion. Ben Highmore said: "while this is an important focus...much more stress is placed on the everyday as a site of resistance, revolution and transformation." (Highmore, 2002:17) Many western thinkers such as Husserl, Wittgenstein, Heidegger, and Lukács in the 20th century had conducted a rational observation or value evaluation of the "world of everyday life", but it was Lefebvre who had a more definite and systematic study on this issue. In the cultural and philosophical sense, he first put forward the modern concept of "everyday life", and gradually formed a critical concept with certainty and systematisms. Debord, who had been involved with Lefebvre, was deeply influenced by him. It has also become an important theoretical source for Debord and Raoul Vaneigem to think about everyday life, and it is finally used as an important entry point for the breakthrough of the Cultural Revolution. He believes that everyday life is the yardstick of all things: In order to obtain its true meaning, every plan starts from everyday life and every achievement must return to everyday life. Like Lefebvre, He Takes the everyday life field as an important battlefield against capitalist rule. It is believed that only by destroying the spectacle with illusory and deceptive nature at the level of everyday life, exposing its alienating nature, making people's life returns to the moment of real life, making the subconscious of the spectacle society visible and understandable, is there a possibility to awaken people in alienation and numbness to battle. He gave bright prospects for the revolution of everyday life in an extremely optimistic spirit.

\section{IV. "DÉRIVE” AND “DETOURNEMENT": THE STRATEGIES OF THE CULTURAL REVOLUTION}

Debord gave the artistic revolution and the everyday life revolution a positive political potential in his criticism of the society, but it seems too grand and out of reach. Therefore, we must put him in the context of situation construction and a microscopic and concrete action strategy to better 
understand the actual potential contained in this dual revolution, because the situation does not exist spontaneously and needs to be constructed, it is embodied in specific experimental action strategies such as "dérive" and "detournement" that run through the art revolution and the everyday-life revolution.

Dérive is a basic tactical practice of SI, "a technique of rapid passage through varied ambience. Dérives involve playful-constructive behavior and awareness of psychogeographical effects, and are thus quite different from the classic notions of journey or stroll." (Debord, 1958) This is a different kind of aggressive strategy from Lefebvre, and it negates the everyday urban life, especially the solidification of the architectural space layout. He cited Chombart de Lauwe's study Paris et l'agglomération parisienne (Bibliothèque de Sociologie Contemporaine, P.U.F., 1952)to prove that this kind of coagulation limits people's lives to a pitiful situation, therefore, a kind of gamelike dérive activity should be carried out. When you devote yourself fully to the exploration of urban terrain, the true desire of perception itself is liberated from the tedium and alienation of everyday urban patterning. It even made some provisions for this: For example, in space, it is best to be a city or industrial area; in time, it is better to be a day; in terms of the number of people, two to three people, and to have more equal awareness; in the climate, storms or other types of heavy rainfall will be more favorable. Under the guidance of this action strategy, Debord and its members of the Situationist International have never tired of this dérive practice in Paris, London, Copenhagen, Rome, Brussels, Germany's Harz Mountains, in many European cities and even in the countryside. It has become a sensation. "An urban neighborhood is determined not only by geographical and economic factors, but also by the image that its inhabitants and other neighborhoods have of it." (Debord, 1958) This shows that in their experience of dérive, they are more likely to use imagination to negate the spectacle that is imposed on people by the solidification space, and they hope to find the true sense of subjectivity in the rigid presentation and combine the geographical exploration and research with emotional disorientation and positioning, and to find a "possible rendezvous" to achieve the dual release of physical and mental depression and sense of emptiness.

The dérive, as Debord himself puts it, is a reconstruction of the feeling consciousness of psychogeography. When this "dérive" strategy is applied to the deconstruction and reorganization of culture or art, it is what he calls "detournement". The usual practice is to implement old works through imitation, citation, collage, and unordered grafting. The formation of this revolutionary strategy is also deeply influenced by the surrealist works. The words in the surrealist works lack logic and normativeness. The coincidence between words and sentences, sentences and sentences is based on accidental coincidences, even with unknown symbols and letters. In the form of representation, it is divided into secondary detournement and deceptive detournement. The former refers to the elemental detournement with no significant value. It only draws meaning from the new context it replaces, such as a new newspaper clipping, a neutral idiom, and the direct use of an ordinary photo in a deliberately created context. The latter is also known as the pre-warning theme of the detournement, which refers to the derivation of a new and different meaning domain from the new context. The basic rules of detournement are as follows: (1) the thing that has a strong influence on the overall impression is the farthest element of the detournement, rather than the element directly determining the nature of this impression; (2) introducing the deformation factors in the elements of different rails must be as simple as possible, because the main effects of different rails are directly related to the consciousness or semiconscious memories of the primitive context of this element; (3) the closer to a rational answer the detournement, the more inefficient it is; (4) with the help of a simple reversal, detournement are always the most direct and least effective. In practice, it is expressed in the fields of literature, art, architectural music, painting, etc. However, he believes that it is possible to achieve its maximum effect in the film arts. This is also highlighted in his movie the society of the spectacle. In 1952, Debord screened his first film Hurlements en faveur de Sade at the Cinemas of the Museum of the Human Museum and the Spiritual Society theater in Region 6. The erotic cues of the title let viewers fall into a reverie, because Marquis de Sade's works, famous for writing pornography, were still banned in French society at that time. However, the 64-minute film has only black and white alternate screens and intermittent narration. The content is nothing more than excerpts of the press, civil law, or famous literary works. The film ends with Debord's sad voice. "We experience an incomplete adventure like a lost child." The screenings were interrupted several times by angry viewers, and Wolman explained in the following audience meeting that this was exactly what the film was expecting! This is the practical application of Debord's detournement strategy in movies. Those seemingly random scenes, those unclear sounding narration, in the appearance of seemingly mischievous, in the challenge of audience viewing habits, create a way for the participants to make a combination of game and philosophy. A fiercely responding social scenario, introducing conflict into public space and disrupting the old value of existence by tweaking the popular intellectual films of the time: simplifying the film to the most essential light and shade, thereby stimulating people to think about art and real life in anger. The distance between them is the Brecht's "off-effect" mentioned earlier. In the same year, John Cage's musical "4'33", 4'33'" tape, was silent and in fact expressed the same meaning.

In the above two revolutionary strategies, dérive is mainly a reorganization of the everyday life of the boring and mediocre city. The detournement is mainly the subversion and rebellious reconstruction of old art, but they are based on the theoretical tenet of unified service in context construction. Both are trying to break the habit of thinking and behavior imposed on people by the spectacle, similar to Russian Formalism's Defamiliarization or Brecht's Estrangement Effect, and in the reflection or shock from the separated false world. The true subjects are restored to resist the implicit control and enslavement of capitalism. 


\section{CONCLUSION}

Guy Debord, although the current researches on him is not as diverse as the Frankfurt School, Lefebvre, Baudrillard and others, it does not mean that he can be marginalized. As Steven Best and D Kellner put it, the efforts of Debord and other members of SI can be thought of as a contemporary French effort to restore Marx's plans, although he himself does not recognize himself as a Marxist. But compared to the Frankfurt School, they are obviously closer to Marx. At the theoretical level, they tried to reactivate Marx's revolutionary practices and supplement Marx's critique of capital and commodities. They then criticized the falsehoods and alienations created by the society of spectacle and tortured the living conditions, sensitively grasped the opportunity and entrance to change, and theoretically analyzed and falsified. On the practical level, he integrated the radical avant-garde spirit into everyday life and art, and in the specific strategies of "dérive" and "detournements". He attempted to summon the real subject and transcend the pessimism and frustration of the Frankfurt School, avoiding the nihilism. There's no doubt that they have shown tremendous theoretical courage and revolutionary potential. This was also reflected in the 1968 student movement. Although many people turned their attention to Marcuse, Lefebvre, etc. In fact, many of the slogans at that time were from SI. For example, "consumer society has to die; dissimilation society has to be good." "To die, we want a new and original world." "We refuse to use a danger of being boring to death in exchange for a world free from hunger." etc.

But Debord's theoretical flaws and the revolutionary utopia tendencies are also obvious. As Debord regards the spectacle as a kind of cultural idol, an all-encompassing and omnipotent amount of cultural hegemonies, and regards it as an absolute, single ideological, lacking John Fiske's dialectic and Diversity inspection. In addition, he and other international members of SI advocate actions such as dérive, detournement, and situationist constructions. It is also a psychological micro-political movement. It is essentially the performance of psychological activism. This revolutionary doctrine is far from Marx's national revolutionary theory; in practice, it lacks feasibility. The change of self-survival state relies on the adjustment of self-conditions in order to achieve overall subversion, which is ideal in itself. Therefore, in the revolutionary strategy and practice, although Debord and the IS members did not indulge, the revolution was psychological, lack of struggle. This also led to the failure of the SI's cultural revolution strategy, and it became the utopian tragedy of mankind's pursuit of aesthetic survival. Accompanied by Debord's act of ending his own life in pain, he has already become the moment of history, but his theoretical achievements are still an important heritage in the history of modern human thought. He led Baudrillard and others in profound and partial Post-modern society's continuing thinking.

\section{REFERENCES}

[1] Bell, Daniel. The Cultural Contradictions of Capitalism, New York: basic books, 1976, P154.

[2] Debord, Guy. The Society of Spectacle. Translated by Fredy Perlman and John Supak. Detroit: Black \& Red,1970, P2.

[3] Marx, Karl. Capital, Beijing: People's publishing house, 1953 volume I, P1

[4] Gorman, Robert A. Biographical Dictionary of Neo-Marxism (London: Mansell Publishing Ltd,1985). Translated by Zhao Peijie. Chongqing: Chongqing Publishing House, 1990, P767.

[5] Debord, Guy. Report on the Construction of Situations and on the Terms of Organization and Action of the International Situationist Tendency, 1957.Guy Debord and the Situationist and International: Texts and documents. Edited by Tom McDonough, The MIT Press, 2010. P29

[6] Debord, Guy. Theses on the Cultural Revolution,1957, Guy Debord and the Situationist and International: Texts and documents. Edited by Tom McDonough, The MIT Press,2010. P91

[7] Highmore, Ben. Everyday Life and Cultural Theory, Thames, Oxfordshire: Taylor \&Francis e-Library, 2002. P17

[8] Debord, Guy. Theory of the Dérive, published in International situationiste \#2,1958. Translated by Ken Knabb, http://library.nothingness.org/articles/SI/en/display/314 